\title{
Multiple visions of the future and major environmental scenarios
}

\author{
Lacroix Denis ${ }^{1,{ }^{*}}$, Laurent Louis ${ }^{2}$, De Menthière Nicolas ${ }^{3}$, Schmitt Bertrand ${ }^{4}$, Béthinger Audrey ${ }^{4}$, \\ David Bernard ${ }^{5}$, Didier Christophe ${ }^{6}$, Parent Du Châtelet Jacques ${ }^{7}$
}

1 Ifremer, Av. Jean Monnet; CS30171. 34203 Sète Cedex, FRANCE

2 Anses ,14 rue P.et M. Curie; 94701 Maisons-Alfort Cedex 01, FRANCE

3 Irstea, 1, rue Pierre-Gilles de Gennes; CS 10030; 92761 Antony Cedex, FRANCE

4 INRA ,147 rue de l'université; 75007 Paris ,FRANCE

${ }^{5}$ CEA ,Le ponant D Bâtiment 885; 25 rue Leblanc; 75015 Paris ,FRANCE

6 Ineris,Parc technologique Alata BP2; 60550 Verneuil-en-Halatte, France

7 Météo-France ,73 av. de Paris; 94165 Saint Mandé Cedex, FRANCE

*Corresponding author : Denis Lacroix, email address : $\underline{\text { dlacroix@ifremer.fr }}$

\begin{abstract}
:
Scientific programming in environmental science often relies on short-term (3 to 5 years) trend-based projections for contextual elements like the demography or the economy to construct or justify its choice of priorities. However, this approach does not take into account numerous factors of change or disruption over a longer term ( 10 to 20 , or even 50 years), although a decade or two are needed to effectively deal with the stakes of research. These stakes become more acute over the long term, as consequences of predicted changes (e. g. climate) or other factors such as pollution, biodiversity erosion, reduction of ecosystemic services.... This complex question justifies turning to a foresight approach. Because it enables tipping points to be envisaged for some key variables of the system studied (in this case, the environment), the scenario method seems well adapted to proposing several contrasting visions of the future.. The research question is: how a large screening of international studies on environmental scenarios can help framing the reflection on research priorities about environment? To help take its strategic reflection forward, in June 2015 the French national research alliance for the environment (AllEnvi) commissioned its transversal foresight group to identify the major families of scenarios described in foresight studies dealing with the environment since 2000. The summary of the 307 scenarios produced by analyzing 99 international studies highlighted 11 possible societal and environmental pathways. Analyzing these families of scenarios thus makes it easier to clarify the multiple roles that science can play, according to contrasting dynamics. Consequently, this study shows how a systematic review of foresight studies and their related visions of the future of environment can stimulate and enlighten the reflection on the ways societies can (re)define their future, by combining environmental, governance and social sciences.
\end{abstract}




\section{Highlights}

- A French foresighters team had been asked to cluster the main environmental scenarios described in international studies. The synthesis of the 307 scenarios described in 99 studies highlighted 11 societal and environmental pathways. Those 11 pathways can be clustered in 3 groups: Decline, No priority to environment, With priority to environment. Governance, economy and societies, in that order, showed to be the main drivers of the scenarios. Ocean, coastal areas and forest are rarely cited as driving factors for environmental scenarios.

Keywords : Research programming, Foresight, Scenarios, Environment, 2100 


\section{Introduction}

Numerous foresight methods have been developed since 1945. In this paper, we take the definition of foresight given by G. Berger (1967): "Foresight is a method to see in the distance in time, broadly, analysing in depth, thinking to human, allowing to take risks". For the public, foresight is frequently linked the concept of scenarios, "series of hypothetical events, which are built to show causal process and decisions at stake" (Kahn and Wiener, 1967). They have often been categorized into various American (Cornish, 2006; Schwartz, 2007...), British (Van der Heijden, 1996; Georghiou et al, 2008...) or French (Godet, 1991; Jouvenel, 2004...) "schools". With hindsight from over 60 years of studies on all subjects, it appears that the choice of a given method is all the more pertinent when it is made with respect to the problem set out, the spatial-temporal framework, the resources made available and the time allotted to supply the results (Mermet, 2005). One of the most fruitful methods in foresight studies is that using scenarios (Bradfield, 2005; Bishop et al, 2007, Bezold, 2010). How rich a scenario will be linked to the number of drivers it has and the variability of its hypotheses (Nowack et al., 2011; Tapinos, 2012; Grienitz et al., 2014). Of course, several other methods can be explored, such as the Delphi, of quantitative models, but the record of scenarios seemed to be more suitable for a systematic review on projected pictures/evolutions of environment at different time horizons. This paper is not a review of foresight 
planning techniques but a broad overview of the results of diverse foresight analyses about the future environment, whatever the techniques used.

Actually, the main challenge for public-sector stakeholders involved in selecting and monitoring research programmes is dual: (1) optimize the impact these programmes have on the targeted objectives (knowledge, technologies, transfers and so on) and (2) strengthen synergies either in-house or between institutions, on national or European levels. One prerequisite is for the stakeholders in question to develop a shared vision of the most relevant research to be engaged, e.g. in the shape of a mediumand/or long-term work programme. A commonly practised method to develop it consists in interviewing expert panels, possibly associated with other stakeholders, then to draw up a summary of the responses. This participatory approach has the advantage of taking account of all research proposals and starting from a wide range of opinions and expert assessments (Nowack et al, 2011). For instance, this is how the national research strategy in France constructed around ten societal challenges based on a vast consultation process (MESRI, 2015) or, in Europe, the working programme which research programming is based on were developed (European Commission Decision, 2017).

However, this type of approach rarely refers to the future world in which programmed research could provide solutions, even though this is one of research's aims (Cazes, 1986). There is a general tendency to rely on an implicit future built upon trend-based projections for the main elements of context (demography, economy, technologies, etc.), i.e., to reason only in terms of trends that are "significant" and thus hard to call into question, on projected situations dubbed "median" which are therefore consensual because they avoid pessimistic scenarios or breaking points. The second disadvantage is that these futures are often constructed in the framework of an approach by field of research and take little account of systemic effects. Finally, the foresight method used with respect to the issue raised is hardly taken into account, whereas it should be thought out from the very outset of work (Könnöla et al, 2011). Choosing the conventional scenario method can itself be debated, using explicit quality criteria (Mietzner and Reger, 2005; Kuusi et al, 2015)

To avoid these structural defects, it is better to adopt another approach, based on "reference" futures defined independently of the research programming and to see how the research could fit into it. A horizon of 2030 or 2050 seems pertinent, because it is not rare to take 20 or 30 years for a technology to reach maturity or societal changes to occur. Furthermore, when dealing with the environment, the relevant scale is often European or global, seeing the broad scope of the mechanisms at play. This sort of approach is implemented, for instance, by the European Commission's Directorate-General for Research and Innovation unit (Burgelman et al, 2014) and foresight exercises are published on a regular basis. Actually, since the 1990s, foresight analysis has been more and more used by governments, and notably European governments, to describe the impacts of human activities on environment (Miles, 2010). This approach is also used for technology, a field where we seek to bring the technology proposed closer to the needs of the future society (Georghiou and Harper, 2011). Apart from their role as a tool to analyze the impact of long-term research, foresight exercises are often a way to spark a dialogue between stakeholders and create networks for future collaborative work.

The aim of this study consisted in constructing "sets of possible futures for environment" using existing exercises and extracting the key variables. The approach is similar in part to that used in the field of technological research by the Danish Agency for Science, Technology and Innovation, which compared 15 key focus areas recommended by a thematic panel with 17 technological foresight exercises (Rasmussen and Dannemand-Andersen, 2009).

The National research alliance for the environment (AllEnvi) brings together 28 French public research institutions whose activity concerns the environment. Allenvi provides support on a national scale to establish research priorities. This leads the Alliance to examine these priorities, through the work of thirteen theme-based groups ${ }^{1}$. In 2015, AllEnvi wanted to complement this work by comparing its programming vision coming from research with representations of futures coming from foresight exercises addressing environmental issues. This approach's objective was to put the research programmes recommended by the thematic groups into perspective. For instance, it can be interesting to see which

\footnotetext{
Agroecology and soil, food and nutrition, biodiversity, plant biology, climate, water, environmental assessment, ecotechnologies, sea, risks, territories, cities and mobility.
} 
future(s) these programmes will best fit, or whether they remain relevant in other, or even all, scenarios, which would make them much more robust. In this way, some programmes can remain highly dependent on a specific scenario, whereas others, like the "no-regrets" choice, can fit acceptably into all proposed scenarios. Another possible approach, symmetrical to the previous one is to start from one or several scenarios of the foresight study and then build the research programme best adapted to the chosen context, i.e. the most probable, most plausible, most global, and so on. Therefore, a systematic review of projections of environment scenarios could help building a robust and international set of potential evolutions of environment to be used by all Allenvi members.

In this way, 99 foresight exercises were selected from international bibliography and direct contacts. These 99 studies entailed in 307 scenarios. In the first part, we describe the method applied to first select the foresight exercises, then extract eleven families of scenarios from this mass of information. These eleven families thus make up eleven visions of the future. In the second part, the characteristics of the eleven families extracted are set out. And finally, in the third part, we discuss the implications for environmental research.

\section{Method}

The method takes its inspiration from the systematic reviews developed especially in the field of biomedicine and in environmental sciences (Bilotta et al, 2014, Higgins and Green, 2011). The work was conducted in three phases: (I) Creating the bibliographic corpus; (ii) analyzing the corpus to create summary sheets per study and per scenario; and (iii) constructing families of scenarios through an iterative process. It is important to underline that this approach is not a review and a critical interrogation of the foresight techniques and approaches within the context of studying the future impact of climate change. These techniques are considered as globally relevant as leading institutions involved in the selected studies are credible and trustworthy (see below the sources). The global frame of evolution (trends, tipping points...) is not limited to the climate change but encompasses several other criteria such as population, economics, resources availability, political (un)stability...

\section{The creation and characteristics of the bibliographic corpus}

It is worth explaining the justification of a qualitative analysis approach. Indeed, a quantitative text analysis could have been envisaged as this approach "can be used in answering questions about what themes occur" (Roberts, 2000). But on the other hand, the selection of qualitative content analysis is all the more justified so as the context is central to the analysis and the interpretation of the corpus of studies (Kohlbacher, 2006). Handling uncertainty is more depending on the capacity to understand consequences of choices than to the accuracy of measure of "state uncertainty" (Vecchiato and Roveda, 2010). This approach highlights the importance of governance as the real responsibility is not in the intentions of an action but more precisely in the consequences of the choices determining this action (Starr, 2002; Weber et al, 2002). These considerations justify to select a qualitative analysis, in addition to the fact that the features of the studies are very diverse (sources, countries, horizons, experts team sizes, institutional frames...). The global process of this type of analysis can be synthesized in three-steps: (1) summary in order to give a comprehensive view of the content; (2) analysis in order to give a clear understanding of the text; (3) structuring in order to assess the material according to certain pre-selected criteria (Mayring, 2014). This had been globally the process of the study.

To draw up the corpus, it was decided that no choice would be made based on the methods followed for the foresight exercises. The working group adopted two rules of selection: first, the studies had to have produced one or more scenarios and second, they had to cover a broad range integrating geopolitical, environmental and socio-economic dimensions. The search of relevant studies was done by specialized librarians from three institutes (Ifremer, Irstea, Météo-France). The group of experts decided to select the studies with key-words and then through collective screening of abstracts. No quantitative meta-analysis of data, or thematic categorization or co-occurrence between topics had been done. The priority was given to an acute reading of the selected documents as the number of studies (99) was manageable by the 12 experts. 
Several databases were used for the exploration of variants of this paper: Web of Science, Scopus, Google scholar, Google, Futuribles. Keywords were: scenario, future, storyline, foresight, foresight study, analysis, prospect, drivers, environment, biodiversity, climate, impact assessment, land use, 2050, 2100, and their equivalent in French

There were two steps to the selection.

The first consisted in creating a corpus of 204 studies identified as being potentially relevant. Many sources were explored: databases of involved institutions, specialized websites, networks of experts (Futuribles, European Foresight Platform, etc.), international organizations (UNESCO, OECD, World Bank, European Commission, UNEP, etc.), foresight journals (Futures, TFSC, EJFR, etc.), and scientific correspondents in the embassies of some twenty countries on all five continents.

The second step was to select the studies which could be used, following specific criteria:

- The possibility of extracting explicit scenarios from the study.

- Dating back less than 15 years, which meant that no study was earlier than the year 2000.

- The environment taken into account in the drivers or the scenario impacts.

- A time horizon situated between 2030 and 2100 (with studies then classified into three categories: 2030, 2050 and 2100).

- A sufficiently large spatial scale, at least that of a medium-sized country; most often that of a large country, large world regions or the world.

- English, French or Spanish used as the study's language.

The studies are then put into three categories, characterized by a weight from one to three. The bigger the region concerned by the study (world, continent, etc.) and the more the environmental themes taken into account are broad and diversified, the higher the weight given to the study (Table 1). Thus, a generalist study targeting the whole world, or a study integrating the effects of global climate change on various environmental compartments on a global or continental scale, would receive a weight of 3 (e.g. Leadley et al, 2010), while studies whose regional scope is limited and only partially take account of the environment would only "weigh" in at 1 in the scenario families development phase (e.g. Raupach et al, 2012). The weight of 2 is given when the position of the study is "medium" as shown on the table 1 (e.g. Adloff et al, 2015) This weighting also takes account of the appraisal of methodological quality and how robust the study is.

Table 1 - System of allocation of weight to the selected studies

\begin{tabular}{|l|c|c|c|}
\hline $\begin{array}{c}\text { Spatial extension } \\
\text { Importance given to environmental issues }\end{array}$ & $\begin{array}{c}\text { small } \\
\text { (country) }\end{array}$ & $\begin{array}{c}\text { medium } \\
\text { (region) }\end{array}$ & $\begin{array}{c}\text { large } \\
\text { (world) }\end{array}$ \\
\hline Little & 1 & 1 & 1 \\
\hline Medium & 1 & 2 & 2 \\
\hline High & 1 & 2 & 3 \\
\hline
\end{tabular}

The work led to the selection of 99 studies which had mobilized a total of approximately 7,700 experts from forty countries, representing 307 scenarios. Features of this set were:

- Most of the studies were commissioned or conducted by public institutions (80\%). The remaining $20 \%$ were divided evenly between private firms and NGOs.

- Studies on a global or European scale (i.e., covering Europe or, in a few cases, a large European country) make up the majority, with respectively 44 and 30 studies out of 99 . The remainder ( 25 studies) concern other regions of the world (see Table 1). Above and beyond the problem of having access to languages of countries whose studies are not often translated into English, French or Spanish, this geographical bias also reveals that few studies are conducted on foresight in general and the environment in particular in emerging countries, which reduces the sources of information. 
- Although the furthest time horizon (2100) is rarely envisaged, it is above all reserved for studies of world scope. On the contrary, the 2030 horizon is most often mobilized in studies whose scope is continental or covers large world regions. At the 2050 horizon, the world and regional scales balance out (see Table 1).

- $\quad$ The studies selected cover a wide range of themes which are explained in Table 2.

- Respectively 33 studies received a weight of 3, 26 a weight of 2 and 40 a weight of 1 , having respectively produced 96,79 and 132 scenarios.

- A variety of so-called "scenario" methods are used in the studies. If we follow the classification made by Bishop et al. (2007), it can be noted that one third of the studies use methods to directly construct logical scenarios through workshops of experts who have the key variables for the issue at their disposal. By order of frequency, then come quantitative modeling based on various algorithms (15\%), followed by morphological analysis combining hypotheses about the variables, drawing up contrasting scenarios and analyzing impacts on stakeholders and sectors (13.5\%), and backcasting (reconstructing the tree chart of choices from a given situation at the chosen horizon (13.5\%). Finally, comes the method of extension of trends, which only provides a single scenario $(10 \%)$. Table 2 is gives examples of the types of scenarios and some details on "model" publication in each category. Tables 3 and 4 show additional information on time horizons, geographical scope and main themes of the studies.

Table 2: Main type of studies analyzed for this systematic review

\begin{tabular}{|c|l|l|l|}
\hline $\begin{array}{l}\text { \% of the 99 } \\
\text { studies }\end{array}$ & Type of method & "Model" study & Main features \\
\hline $\mathbf{3 3}$ & Logical scenarios & $\begin{array}{l}\text { European } \\
\text { Commission, 2017 }\end{array}$ & $\begin{array}{l}\text { Practicioner; 3 main scenarios crossed with } \\
\text { 6 domains (population, economy..); scan of } \\
\text { consequences for Europe }\end{array}$ \\
\hline $\mathbf{1 5}$ & $\begin{array}{l}\text { Quantitative } \\
\text { modeling }\end{array}$ & $\begin{array}{l}\text { Neumann } \text { et al, } \\
\text { 2015 }\end{array}$ & $\begin{array}{l}\text { Academic; risks analysis to flood exposure } \\
\text { from existing database }\end{array}$ \\
\hline $\mathbf{1 3 . 5}$ & $\begin{array}{l}\text { Morphological } \\
\text { analysis }\end{array}$ & Godet, 1991 & $\begin{array}{l}\text { Academic; a description of multi- } \\
\text { disciplinary and cross-cutting approach at } \\
\text { various horizons }\end{array}$ \\
\hline 10 & Backcasting & Leadley et al, 2014 & $\begin{array}{l}\text { Academic; mix of trends, Aïchi goals \& } \\
\text { related priorities / recommendations }\end{array}$ \\
\hline & Trends extension & Grienitz et al, 2013 & $\begin{array}{l}\text { Academic \& practitioner; crossing of 5 } \\
\text { drivers, including environment, with trends } \\
\text { of migrations to 2050 }\end{array}$ \\
\hline
\end{tabular}

The objective is that this multiplicity of approaches and stances will make the conclusions drawn more robust. Indeed, a foresight exercise may be biased by the type of entity ordering it, its framing, its objective and the method, especially when it integrates major geopolitical stakes (Eriksson and Weber, 2008; Havas et al, 2010). However, seeing the above-mentioned limitations, this study's visions of the future above all comprise "western world" and rather "public-sector" visions of the Earth's possible futures, slightly enlarged to visions of NGOs or private companies and those in Africa, Latin America or Asia. 
Table 3 - Breakdown of 99 foresight studies in the final corpus according to their time horizon and the geographical area considered

\begin{tabular}{|c|c|c|c|c|}
\hline $\begin{array}{ll}\text { Geographical area } & \text { Time horizon } \\
\end{array}$ & 2030 & 2050 & 2100 & Total \\
\hline World. & 12 & 21 & 11 & 44 \\
\hline Europe & 16 & 12 & 2 & 30 \\
\hline Other world regions including: & 15 & 10 & - & 25 \\
\hline - North Africa \& Middle East & 4 & & & 4 \\
\hline - Sub-Saharan Africa & 3 & 1 & & 4 \\
\hline - North America & 3 & & & 3 \\
\hline - Central and south America & 1 & 4 & & 5 \\
\hline - Asia & 3 & 4 & & 7 \\
\hline - Oceania & 1 & 1 & & 2 \\
\hline Total & 43 & 43 & 13 & 99 \\
\hline
\end{tabular}

Table 4: Breakdown of 99 foresight studies according to their subject and AllEnvi themes (Since some studies address several themes, the sum of studies is greater than 99).

\begin{tabular}{|l|c|c|c|c|}
\hline & \multicolumn{3}{|c|}{ Time horizon: } & Total \\
\hline Themes & $\mathbf{2 0 3 0}$ & $\mathbf{2 0 5 0}$ & $\mathbf{2 1 0 0}$ & $\mathbf{3 6}$ \\
\hline Generalist & $\mathbf{2 6}$ & $\mathbf{1 7}$ & $\mathbf{3}$ & 2 \\
\hline Agroecology and soil & 1 & 1 & & 12 \\
Food and nutrition & 2 & 10 & & 0 \\
Animals in their environment & & & 1 & 2 \\
Biodiversity & & 1 & 5 & 0 \\
Plant biology & & 2 & 2 & 12 \\
Climate & 5 & 8 & & 13 \\
Energy & 5 & 2 & 1 & 2 \\
Water & & 1 & 1 & 2 \\
Environmental assessment & 1 & 1 & 2 & 3 \\
Ecotechnologies & 2 & 2 & & 7 \\
Sea & 3 & 1 & & 3 \\
Risks & 1 & & & \\
Territories \& natural resources & 3 & & & \\
Cities and mobility & 2 & & & \\
\hline
\end{tabular}

\section{Analyzing the corpus and drawing up summary sheets}

The working group then made a detailed analysis of each study in the corpus. A summary sheet template was drawn up, then tested on a small number of studies before generalizing its use. There are two parts to the summary sheet, or fiche:

The first is called a "foresight sheet" and contains the study's general features: author, time horizon, geographical area, who requested it, method used, number of experts, and so on.

The second, called a "scenario sheet", analyzes each scenario in the form of a standardized synthesis which also includes a brief summary of the scenario. Each scenario summary gives the list of drivers, i.e. the factors triggering the series of events making up the scenario. The drivers were selected from a list of six major drivers from the DEGEST grid proposed by E. Cornish in 2006: (i) Demography, (ii) Environment, (iii) Governance, (iv) Economy, (v) Society, (vi) Technology. Cornish showed that the drivers of most of the foresight studies can be limited to this list of six major elements. This classification system has proved to be robust, since an initial seventh category called "Others" was not utilized. These driving forces, or "DEGEST" drivers, which are not always clearly defined by study authors, were identified by the experts. Great care was taken to separate the causes and consequences (for example, deterioration of the 
environment can be a driver if it leads to raising awareness or can be a consequence following inaction by stakeholders).

This work produced 99 foresight sheets and 307 scenario sheets. On average, each study describes 3.1 scenarios, with the number varying from 1 (for studies which simply describe a trend-based scenario) to 9 for the most "creative" study. So, each scenario sheet makes up the basic material for the following steps of the analysis.

\section{Constructing families of scenarios through an iterative process}

The following step consisted in analyzing the proximity between the 307 scenarios in order to group them into families. It proved impossible to reliably implement a quantitative study, seeing the heterogeneous nature of the studies which prevented us from constructing indicators which could characterize the scenarios. Therefore, a qualitative method was chosen, carried out in three phases.

In the initial phase, the scenarios were classified with respect to drivers. After an adjustment period, it was decided to limit the number of drivers to be extracted for each scenario summary to one or two. Each scenario sheet was reviewed and the two (or one at the minimum) drivers which seemed most dominant were extracted. Since some subjectivity is involved in this operation, each sheet was analyzed by at least two people to reduce any bias in the assessment. Thus, all choices of drivers were discussed. The outcome of this analysis is presented in Table 5. The three most frequent pairs of drivers are Governance-Economy (85 cases out of 307), Governance-Society (61 cases) and GovernanceEnvironment (31 cases). It is sometimes difficult to separate which factor is the first and which the second, and in the following breakdown and analysis, pairs (like Governance-Economy and EconomyGovernance) were considered together.

In the second phase, the analysis of scenarios was performed box by box in Table 3, by twelve people divided into three parallel working groups. Therefore, each group processed about 8 boxes, with the symmetrical boxes considered together. Logically, it was expected that similar scenarios would involve the same drivers, in other words, that juxtaposing the results from the three working groups would provide a good initial approximation for distributing similar scenarios into families. This first analysis resulted in a set of 44 "tribes" (to use a different word than family, reserved for use in the final outcome), each tribe gathering on average 8 scenarios ruled by the same two drivers and showing significant similarities.

The third phase consisted in collective work by the twelve experts, aiming to compare these tribes. The key element was to simultaneously display the characteristics of these 44 tribes. Each of them was summed up on a board by a simple title and a dozen keywords. At the end of this collective iterative process, it was possible to group the tribes into 11 families each having from 15 to 49 scenarios.

Table 5: Breakdown of $\mathbf{3 0 7}$ scenarios according to their first two driving factors

\begin{tabular}{|c|c|c|c|c|c|c|c|}
\hline \begin{tabular}{|l|} 
Factor $\mathrm{N}^{\circ} 2$ \\
Factor $\mathrm{N}^{\circ} 1$ \\
\end{tabular} & \begin{tabular}{|c} 
Demograph \\
ics \\
\end{tabular} & Environment & Governance & Economy & Society & $\begin{array}{c}\text { Technologies } \\
\text { \& science } \\
\end{array}$ & \begin{tabular}{|c|} 
Total \\
priorities 1 \\
\end{tabular} \\
\hline Demographics & & & 4 & 6 & 1 & 1 & 12 \\
\hline Environment & & 4 & 18 & 8 & 8 & 2 & 40 \\
\hline Governance & & 13 & 12 & 48 & 37 & 15 & 125 \\
\hline Economy & 3 & 11 & 37 & 3 & 10 & 12 & 76 \\
\hline Society & 1 & 3 & 24 & 10 & & 5 & 43 \\
\hline $\begin{array}{l}\text { Techno \& } \\
\text { science }\end{array}$ & & 1 & 2 & 2 & 6 & & 11 \\
\hline Total priorities 2 & 4 & 32 & 97 & 77 & 62 & 35 & 307 \\
\hline
\end{tabular}

\section{Unequally weighted drivers.}

Table 6 presents an analysis of the 614 drivers, i.e. two "DEGEST" drivers per scenario (it was agreed that a scenario with only one, i.e. thus situated on the diagonal; would be counted twice). Significant differences in the influence of the driving factors are seen. Out of a total of 614 drivers identified (307 
scenarios X 2 "DEGEST" drivers), governance is present in $36.2 \%$ of cases. Economy follows as the second explanatory dimension with $24.9 \%$, then Society with $17.1 \%$. Environment (11.7\%) and Science and Technology (7.5\%), although often present in the scenarios, are rarely among the top two drivers. And Demography (2.6\%), often seems to be take into account indirectly, through the consequences it may have on the other components rather than in its own right. It seems that some drivers are not symmetrically distributed, as playing the first or second role. This is the case for governance or demography, which are considered as the prime factor when they appear, whereas society or technology come second (See Table 5).

Table 6 - Analysis of driving factors

\begin{tabular}{|c|c|c|c|c|}
\hline $\begin{array}{c}\text { Driving factor } \\
\text { ("DEGEST" driver) }\end{array}$ & $\begin{array}{c}\text { Frequency of } \\
\text { appearance }\end{array}$ & As first factor & $\begin{array}{c}\text { As second } \\
\text { factor }\end{array}$ & $\begin{array}{c}\text { Difference between 1st and 2nd } \\
\text { factor (at 5\% risk) }\end{array}$ \\
\hline Governance & $36.2 \%$ & 125 & 97 & yes \\
\hline Economy & $24.9 \%$ & 76 & 77 & no \\
\hline Society & $17.1 \%$ & 43 & 62 & yes \\
\hline Environment & $11.7 \%$ & 40 & 32 & yes \\
\hline $\begin{array}{c}\text { Technology } \\
\text { \& science }\end{array}$ & $7.5 \%$ & 11 & 35 & yes \\
\hline Demography & $2.6 \%$ & 12 & 4 & \\
\hline
\end{tabular}

\section{Results. 11 families of scenarios with contrasting paths}

\section{The 11 families}

The distribution of 307 scenarios into 11 families enables the narrative of the future to be told for each family by specifying the part played by science and technology, as well as the general consequences these pathways have on the environment.

Each family is based on a sufficient number of scenarios to avoid being overly linked to the use of the same method, a too-limited expert panel, an overly specific issue, a particular time horizon or an excessively narrow societal context. The 11 families can be classified in three groups: "Decline"», "Without environmental priority", "With an environmental priority".

The group of three families of decline. They describe grim futures, marked by tensions between countries and blocks of countries, multiplication of regional conflicts or even generalized conflicts, and in an extreme case, the disappearance of mankind. Three situations are envisaged:

- Chaos: Failure and lack of anticipation by governance, leading the world into spirals of negative synergies generating more or less widespread conflicts and at worst, mankind almost disappearing.

- Withdrawal: the rise of nationalism in the face of economic hardship, competition for resources and migration exacerbate conflicts and national withdrawal in an overall context of political and economic isolationism.

- Fragmentation: individual and collective "selfishness" leads to a multipolar and unequal world with strong lines of fracture and tension; an example being a divided, dual world like "North/South" or "Rich/Poor".

The group of three families without environmental priority. This is characterized by the absence of longterm considerations, and particularly the risk of degrading the environment. Sometimes, pursuing other objectives enables improvements to be made, or environmental deterioration to be limited (for instance, the development of renewable energies to ensure energy independence). This group contains three families:

- Inertia/Business as usual: extension of trends without breaking points, lack of strong commitment towards the environment, either due to lack of financial means, or due to political and societal deadlocks, leading to increased powerlessness and potentially serious environmental consequences. 
- Growth at all cost: here, the environment is sacrificed to economic growth, based either on economic liberalism supported by policies of deregulation or a strong State, or on an active policy of innovation with short-term objectives and goals of profitability.

- Priority to social dimensions: the main objective is to reduce social inequalities by implementing policies of inclusion or redistribution, which can have positive effects on the environment without that being the direct aim.

The group of five families displaying an environmental priority: This group contains various pathways used by humans attempting to improve their environment.

- Reaction: disasters or crises result in rulers' greater awareness of the urgency to take action for the environment: there is no other option.

- Green growth: Policy-makers act to reconcile economic growth and preservation of the environment or to set up the energy transition. In some scenarios, this trend is orchestrated by enlightened global governance.

- Proactiveness: States anticipate, coordinate and act for the environment; increasingly welleducated and informed citizens back these dynamics and support the curve of general well-being and that of consumption breaking away from each other.

- Positive synergies: social consensus in favour of the environment and general and long-term stakes lead to changing values and lifestyles with greater sobriety and solidarity.

- Local: in the face of failure by national or supranational levels of governance or defiance with respect to them, citizens get organized locally to act for the environment, relying, more or less successfully, on local dynamics.

It should be mentioned that there are three scenarios that could not be classified, describing convergence or evening merging of info-bio-nano-technologies, robotics and networked artificial intelligence. The outcome is at best, a "wikidemocracy" made up of social networks of citizens, but where happiness can only exist individually, and at worst, a hyper-urbanized, non-egalitarian, violent society, where the concept of family has disappeared. This small number can be explained by the choices made when the corpus was created. Ruling out books or studies that express a vision more like that of a science-fiction than one of collective foresight work eliminates many publications highlighting technoscientific imaginary worlds.

\section{The 11 families represented in a plan}

When the scenarios were distributed into families it appeared that two of the most structuring characteristics for the analyses in the AllEnvi context were, on the one hand, governance (the driver most often cited), and on the other hand, the way the environment was taken into account (a preoccupation for the AllEnvi alliance). This approach justifies to use the quadrant methodology as the crossing of two major trends facilitate the construction, and the comparison in this case, of several scenarios using various "seed topics" inside each quadrant. This methodology is shown to be better suited to the exploration of high order societal and environmental issues (Raven, 2013). This way of summarizing complex and multiple scenarios at a higher level of governance, notably when considering the infrastructural systems, had been notably developed in special issues about creating prototyping (Graham et al, 2013). This this study, "prototypes" of scenarios are given by the 99 studies and the "seed topics" are similar to the "driving factors".

The efficiency of governance is a driver mentioned in nearly three-fourths of the scenarios. However, this concept takes on multiple forms, since, depending on the geographical scale, it is related just as well to cooperation on the global scale, where States collaborate, as to the existence of strong States with sovereign power of decision. The priority is given to the "State-controlled" conception of governance, but this is not an exclusive concept. De facto, although it is the States which vote on United Nations resolutions, and negotiate and sign binding bilateral or multilateral agreements, they must, depending on the scenario still compromise with other stakeholders. These can be multinational corporations whose turnover exceeds the GDP of a host country, which can lead to strong pressures on the environment, or mafia-type groups who cultivate their popular support. Moreover, state-controlled governance is often 
combined with social dynamics and initiatives from an evolving civil society. When society carries little weight, the scenarios are first structured by public policies sponsored by States ("Green growth"), whereas a "State-society" pact can lead to pathways of the "Proactiveness" or "Positive synergies" type. Sometimes States are weak and local stakeholders take the initiative. This is the case in the "local" or "chaos" family pathways.

Even though, paradoxically, the environment is only put forward as a driver a fourth of the time, the nature of the priorities that stakeholders grant it strongly determines the overall pathway:

- Hence, in a large number of scenarios, States display their environmental priorities in a proactive way. Depending on the case, these priorities are more or less combined with other economic and social priorities for purposes of growth, maintaining lifestyles, and more rarely sobriety and restraint.

- In other scenarios, stakeholders are betting on the economy, regardless of the consequences. This often means producing wealth, but sometimes, reducing social inequality is what is at stake. A point to be noted is that reducing social inequality is only rarely associated with environmental priorities, as if it was impossible to envisage combining the economic, social and environmental dimensions otherwise than in pairs.

The dispersal of the eleven families illustrated in Figure 1 shows that there is no single pathway, either to improvement or to deterioration of the environment, but that several paths exist, including to rise to the challenges of environmental stakes. However, the vision of environmental preoccupations they give is generally pessimistic. The families can be represented in an approximate way, on a graph crossreferencing the intensity of governance and the general quality of the environment, as the subject of the study (see Figure 1).

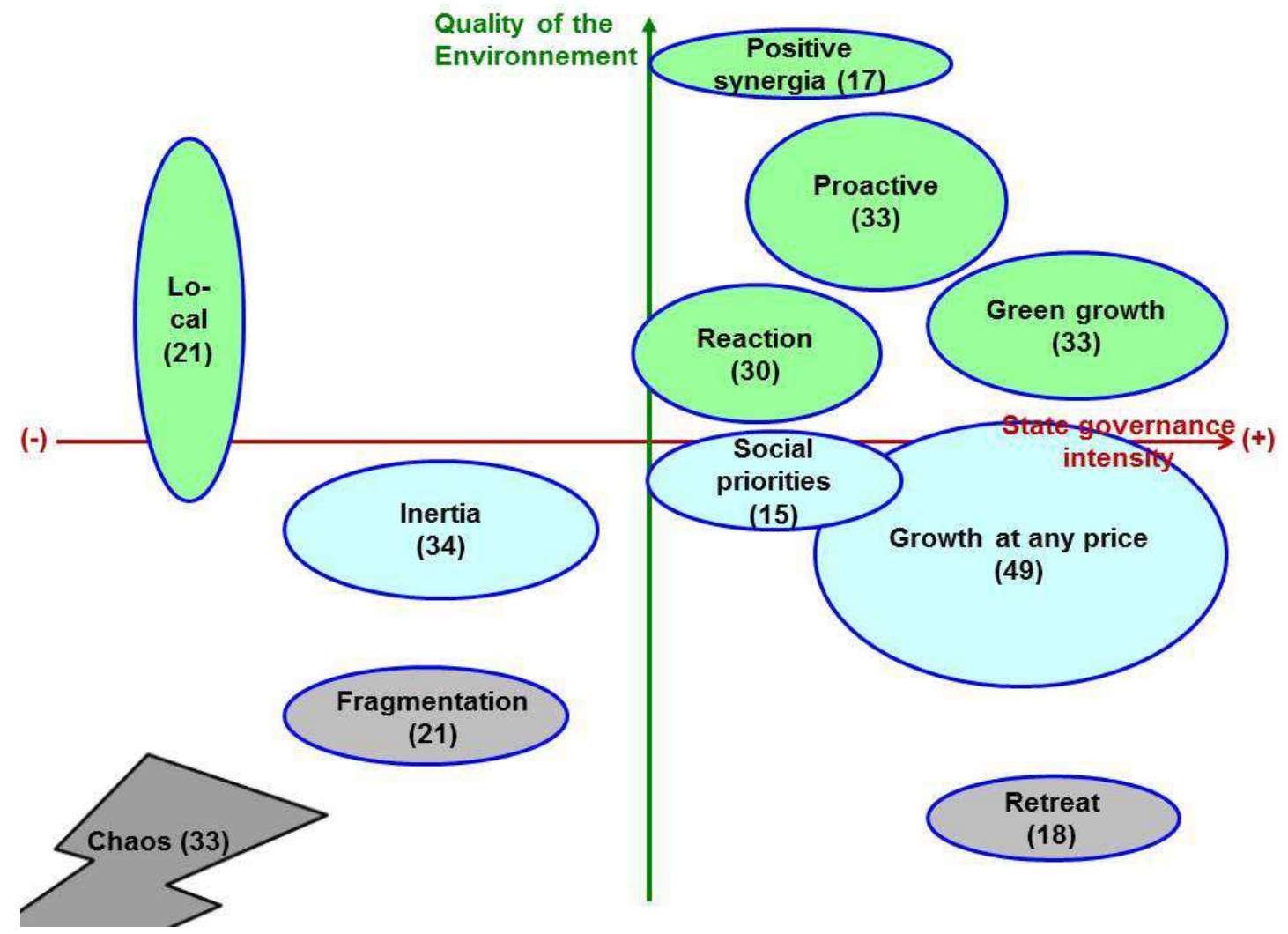

Figure 1 - Positioning the 11 families in the set of axes "Intensity of State governance" and "Quality of the Environment" (the number of scenarios in each family is indicated in parentheses ) 
To verify how robust the representation of possible futures constructed from these 11 families is, it is interesting to examine how some major scenarios that are global benchmarks are positioned on this diagram.

- The four reference scenarios for the IPCC's fifth cycle of work, for Representative Concentration Pathway (RCP)s, for greenhouse gas (GHG), for ozone and aerosol precursors for the 21st century and beyond (Moss et al., 2010).

- The five socio-economic pathways from the same IPCC working cycle, scenarios from economists, political scientists and sociologists, called Shared Socio-economic Pathways (SSP) proposed to represent various patterns of economic development combined with strategies for adaptation and mitigation (O'Neill et al, 2015)

- The four foresight scenarios established between 2001 and 2005 by the international MEA (Millennium Ecosystem Assessment, 2005) expert working group.

Table 7 indicates the correspondences between the eleven families from this study and these reference scenarios. It can be noted that most of the families are covered, with the exception of the most pessimistic (chaos) and the most optimistic (positive synergies). Likewise, we note that two of the MEA scenarios appear twice, insofar as they borrow characteristics from both families, i.e. on Figure 1 they appear at the interface between Proactiveness-Reaction or Proactiveness-Green growth.

Table 7: Positioning of RCP, SSP and MEA scenarios with respect to the eleven families

\begin{tabular}{|l|c|c|c|}
\hline Scenario family & $\begin{array}{c}\text { IPCC- } \\
\text { RCP }\end{array}$ & $\begin{array}{c}\text { IPCC- } \\
\text { SSP }\end{array}$ & MEA \\
\hline Chaos & RCP 8,5 & & \\
\hline Withdrawal & & SSP-3 & Order from strength \\
\hline Fragmentation & RCP 6 & SSP-4 & \\
\hline Inertia/BAU & RCP 6 & SSP-2 & \\
\hline Growth at all cost & RCP 6 & SSP-5 & \\
\hline Social priorities & & & \\
\hline Reaction & RCP 4,5 & & \begin{tabular}{c} 
Global orchestration \\
Adapting mosaic \\
\hline Local
\end{tabular} Pechno garden \\
\hline Pathways towards Green Growth & & & $\begin{array}{c}\text { Global orchestration } \\
\text { Techno garden }\end{array}$ \\
\hline Proactiveness & RCP 2.6 & SSP-1 & \\
\hline Positive synergies & & & \\
\hline
\end{tabular}

A point to notice is the that the north-west quadrant of Figure 1 is almost empty, indicating the absence of scenarios for environmental quality progressing with a low intensity of State governance, except for the case of extreme withdrawal towards local functioning. This situation, popularized by the expression "Think global, act local" was identified as of the 1970s by numerous authors from various horizons (Illitch, 1971; Passet, 1979; Viveret, 2003; Schwartz, 2007; Morin, 2011). One possible explanation lies in the choice made at the outset of the exercise, to only consider exercises covering a broad geographical area (a large country, at minimum). This excludes studies focused on infra-national scales, such as municipalities or major cities. If such studies had been present, they most likely would have supplied scenarios that highlight the role of the local level in collaboration with the State to find environmental solutions.

\section{Effect of framing in foresight exercises}

One question concerns the impact of the choice of time horizons and spatial perimeters in foresight exercises. It is similar as regards the distribution of time horizons over the three sets of "Decline", "Environmental priority" and "Without environmental priority". However, an over-representation of long time periods in the decline scenarios can be noted. It is as if those experts who tend to make projections into a distant future have a known bias of (un)desirability (Ecken et al, 2011). There is also an overrepresentation of short time periods in the "environmental priority" scenarios, which can be explained by the same bias, but also because a reaction to influence the climate situation has to occur in the relatively 
short term, it is logical that these scenarios take place over short time periods. Policy makers also like this "scenario planning" type of approach because a relatively short time scale facilitates setting out the possible choices and traceability of decisions (Meissner and Wulff, 2013).

The distribution of geographical zones varies from one set to another. European exercises seem more optimistic, insofar as they highlight fewer decline scenarios and more "environmental priority" scenarios (Duckworth et al, 2016). The opposite trend is observed for world-scale exercises, which are more pessimistic since their scenarios make up $60 \%$ of the 72 decline scenarios. Logically, at this scale an overrepresentation of "fragmentation" type scenarios are also observed.

As for the weighting of scenarios (i.e., combining the complete nature of the study and the importance given to the environment) a strong over-representation of high-weight studies is observed in the decline scenarios. This observation bears out the link between studies with a high weight, and thus tending to global coverage, and the prevailing pessimism in them.

The very nature of this work must also be taken into account. Foresight exercises aim to clarify contrasting scenarios. So, they have a tendency to exaggerate or caricature. It can be thought that in some of these exercises, the experts tried to highlight the threats that societies must cope with (and therefore the necessary adaptations) if they allow environmental degradation to continue. This approach aiming to educate and inform leads to reinforcing the representation of extreme evolutions in the Decline families. It helps strengthen the potential reactivity of stakeholders, whether politicians or companies, thanks to better advance knowledge and understanding of opportunities and threats alike (Vecchiato, 2012).

\section{What observations can be made for the role of research?}

Research and technological innovation are only drivers in $15 \%$ of the scenarios (see Table 3) and most often as priority 2. However, their role is more important than their poor weighting in terms of drivers. Indeed, the role played by science in these scenarios can be analyzed in various ways, with a range of implications for research programming.

Informing: Science's most important role is to characterize climate change or environmental deterioration and to inform, or even alert, those involved in governance and society on the whole. This role is masked, because in this case the environment is put forward as a driver, associated with governance, economy or society, depending on which stakeholders are acting. This makes it necessary to analyze the 68 scenarios where the environment is a driver in greater detail. Two large categories with a similar weight: perspectives for climate change and general environmental status are predominant here. In both cases, anticipated crises are taken into account. Even though the role played by science in initializing the trajectories is not explicitly mentioned, in the narratives we can often sense the effects of the efforts the scientists in question deploy, particularly in climate studies, to alert public opinion and decision-makers about global changes underway, their potential consequences and how important human activities are in the disruptions ahead. This is the case in the Proactiveness, Reaction and Positive synergy families. However, the grim outlook for the climate described by experts does not always lead to pathways with an environmental priority, but, on the contrary, sometimes result in scenarios of decline or scenarios without environmental priority, which are close to "Inertia/Business as usual" or "Growth at all cost". In these visions of the future, the warning sign of environmental imbalance is the climate. The other environmental stakes, like biodiversity (in 16 scenarios), pollution, not including greenhouse gases (14), soil degradation (13), fresh-water resources (9) and forest resources (7) are less represented. As for the status of the ocean or regional seas, this was never mentioned as the driving force in a scenario.

Providing solutions: In the optimistic pathways, science and technology also play a part as "suppliers of solutions". That said, their role can remain discreet and just be discerned behind scenarios for reducing fossil fuel consumption, substituting non-sustainable resources or improving agronomic yields. It should be emphasized that these solutions only make sense if they are deployed on a large scale, sometimes in crisis contexts where the world is fragmented, or where States are weak. In one part of the scenarios (such as in the "local" family) this means implementing rustic techniques which can be deployed without national or European scale technological infrastructures. 
Contributing to growth: Science and technology also appear as a factor contributing to economic prosperity with two-sided role, sometimes associated with Growth at all cost scenarios, but also as tools to move towards ecological transition or to seek food self-sufficiency in areas where these resources are limited.

Remedying: This function is not often mentioned, even though 219 scenarios describe deteriorated environmental situations. We can imagine that in such futures, the availability of adaptive or remedial solutions will be actively sought. Indeed:

- Climate concerns rank first in 95 scenarios, with an unfavourable outcome in $43 \%$ of cases.

- Management of non-renewable natural resources (including energy resources) is mentioned 81 times. In two-thirds of the cases, the situation improves through a transition to sustainable management.

- While not often considered as drivers, biodiversity and pollution (not including GHG) are each mentioned about sixty times as the environmental consequence of scenarios. They tend to evolve towards degradation almost as often as towards improvement, depending on the type of family.

- Although the scenarios' consequences on water and land resources are also examined quite often, their trends go almost exclusively towards degradation, both in quantity and quality. These pessimistic visions for these two components suggest that analysts consider that some irreversible aspects have already been reached and that even scenarios which display an environmental priority will not be able to prevent or curb their degradation.

- It should be highlighted that there are few scenarios (13\%) concerned with the consequences for Forests (10 times) and above all for the Ocean (17 times). Even though a few scenarios envisage the restoration of forest ecosystems, in almost every case, marine and coastal ecosystems are considered to be deteriorating, as are the resources in soil and, to a lesser extent, fresh water.

\section{Conclusion}

This study was conducted within the alliance of environmental research institutions in France (AllEnvi). It aimed to put research in the framework of major scenarios looking at the environment on the horizon from a few decades until 2100 , for the world and large world regions, into perspective. the usefulness of such study can be linked to the fact that the use of multiple scenarios actually does not change the confidence of experts in their judgments but, as it provides new pros and cons, "it nudges experts to more flexible strategies", including judgment change (Phadnis et al, 2014). Rather than perform a specific foresight exercise, the choice was made to analyze a corpus of 99 recent foresight studies (dating back less than 15 years), predominantly global or by large region, which had involved approximately 7,700 experts in over 40 countries. The idea justifying the approach was that the diversity of these studies would enable analytical bias to be reduced and large sets of future visions structuring this panorama to be discerned.

The 307 scenarios extracted from these 99 studies were analyzed by setting out 6 drivers proposed in the framework of the DEGEST (Demography, Environment, Governance, Economy, Society, Technology) method. An iterative classification method produced eleven families of scenarios in which those produced by the IPCC or the MEA easily find their place. These eleven families can be gathered into 3 groups: decline, without environmental priority and with an environmental priority. Generally speaking, these scenarios are rather pessimistic, even when environmental degradation is taken into account.

In these narratives of the future, the main drivers are governance, the economy and society, in that order. Science and technology occur as the dominant factor in only $15 \%$ of cases. Nevertheless, this set of scenarios provides a panorama of the possible roles science can play. The first role assigned to it (sometimes implicitly) in the narratives is to alert and then enlighten the stakeholders who are setting change in motion. Sometimes in these narratives, science supplies solutions, for instance to limit the wasting of resources, reduce greenhouse gas emissions or improve agronomic yields. Finally, many scenarios consider than the degradation of water and land resources is inevitable, thus revealing the risk 
of irreversibility. Then science is called upon to provide solutions for remediation or adaptation. Some of the futures take place in fragmented worlds with fewer resources and rather weak forms of governance.

The limits of the study are linked to the representativeness of the studies which were identified and selected. While it is undeniable that grouping the scenarios into large families reduces the risk of methodological biases, the study remains tinged by a more western representation of the world, especially coming from international public-sector or para-public organizations. A lack of endogenous studies for Asia and Africa is seen. Finally, the fact that studies conducted by infra-national institutions (regions, major cities, towns, etc.) were not taken into account could explain in part the lack of at least one family of scenarios comparing a certain effectiveness in improving the environment and significant sharing of responsibilities between levels of governance, which would make it possible to reduce or better relay the role played by the State. Networks of citizens (participatory sciences, crowdfunding, etc.) have not yet been recognized as being capable of influencing the future of their environment over the past 15 years.

For practice, the usefulness of the study for long-term reflections about scientific programming and the description of the 11 scenario families are progressively being acknowledged, because it can provide any working group or decision-maker with a range of plausible scenarios, which can be adjusted with respect to the spatial scope being considered and its time horizon (Burgelman et al, 2014). Therefore, it can play a dual role: first passive, in calibrating existing scientific programmes, and then active, in choosing research priorities for a given organization, region or horizon. This approach facilitates a more global overview of a complex question, as it takes into account several points of view from different countries and continents, and also on a 15 years time interval. It is noteworthy to record only three scenarios of a new world war among a total of 307. It is also a good way to weigh various families of scenarios and notably to observe that the economic growth ("at any cost") remains the major framework of environment evolution. This kind of finding helps selecting appropriate science priorities and suitable research policies.

\section{Acknowledgements}

The authors warmly thank Pascale Hénaut (Irstea), Morgane Le Gall (Ifremer), Marie-Hélène Pépin (Météo-France), Isabelle Pradaud (Ineris), Hervé Hanin (SupAgro), Marie de Lattre-Gasquet (Cirad), Florence Carré (Ineris), Flora Pelegrin (FRB) and Virginie Piguet (INRA), who actively contributed to collecting the studies and to analyses and discussion at various stages of this work, including the processing of data. The working group also thank the Alliance nationale de recherche pour l'environnement (AllEnvi, FRANCE) for the selection of this first topic for foresight analysis and the constant support in this study.

\section{References}

Adloff F., S. Somot, F. Sevault, G. Jordà, R. Aznar, M. Déqué, M. Herrmann, M. Marcos, C. Dubois, E. Padorno, E. Alvarez-Fanjul, D. Gomis, 2015: Mediterranean Sea response to climate change in an ensemble of twenty first century scenarios. Clim Dyn (2015) 45:2775-2802; 1-3; DOI 10.1007/s00382015-2507-3

Berger G., 1967: Etapes de la prospective. Paris. Presses universitaires de France

Bezold C., 2010: Lessons from using scenarios for strategic foresight. Technological Forecasting and Social Change. 77(9):1513-18

Bilotta G.S., Milner A.M., Boyd I., 2014: On the use of systematic reviews to inform environmental policies. Environmental Science \& Policy. 42:67-77

Bishop P., Hines A., Collins T., 2007: The current state of scenario development: an overview of techniques. Foresight. 9(1):5-25

Bradfield R., Wright G., Burt G., Cairns G., Van Der Heijden K., 2005: The origins and evolution of scenario techniques in long range business planning. Futures. 37(8):795-812 
Burgelman J.C., Chloupková J., Wobbe W., 2014: Foresight in support of European research and innovation policies: The European Commission is preparing the funding of grand societal challenges » Eur J Futures Res (2014) 2:55

Cazes B., 1986: Histoire des futurs: les figures de l'avenir de Saint Augustin au XXle siècle. Editions Seghers ISBN 978-2232100529

Cornish E., 2006: Futuring: The Exploration of the Future. Bethesda, Md: World Future Society; ISBN 9780930242619

Duckworth M., Lye D., Ravetz J. and Ringland G., 2016. Strategic Foresight: Towards the 3rd Strategic Programme of Horizon 2020. Luxembourg: Publications Office of the European Union.

Ecken P., T. Gnatzy, H.A. von der Gracht, 2011: Desirability bias in foresight: Consequences for decision quality based on Delphi results. Technological Forecasting and Social Change Vol. 78, Issue 9: 16541670

Eriksson E.A., Weber K.M., 2008: Adaptive Foresight: Navigating the complex landscape of policy strategies. Technological Forecasting and Social Change. 75(4): 462-82

European Commission Decision, 2017: Horizon 2020 Work Programme 2016 - 2017. Climate action, environment, resource efficiency and raw materials. https://ec.europa.eu/research/participants/data/ref/h2020/wp/2016_2017/main/h2020-wp1617climate_en.pdf

Georghiou L., J. Cassingena Harper, M. Keenan, I. Miles, R. Popper (Eds), 2008: The handbook of technology foresight: Concepts and practices. Edward Elgar Publishing. Cheltenham UK

Georghiou L., J. Cassingena Harper, 2011: From priority-setting to articulation of demand: Foresight for research and innovation policy and strategy. Futures 43 (2011) 243-251]

Godet M.,1991: De l'anticipation à l'action: manuel de prospective et de stratégie. Paris: Dunod. ISBN 978-2-10-000145-3

Graham G., A. Greenhill and V. Callaghan, 2013: Technological Forecasting and Social Change Special Section: Creative prototyping. Technological Forecasting and Social Change. 84 (2014)1-4. doi: 10.1016/j.techfore2013.11.007

Grienitz V, Hausicke M, Schmidt A.M., 2013: Scenario development without probabilities - focusing on the most important scenario. Eur J Futures Res. 2(1):1-13GOS, 2011: Foresight: Migration and Global Environmental Change. Final Project Report 234 p. The Government Office for Science, London. UK

Havas A., Schartinger D., Weber M., 2010: The impact of foresight on innovation policy-making: recent experiences and future perspectives. Research Evaluation. 19(2):91-104

Higgins J.P.T., Green S., 2011: Cochrane Handbook for Systematic Reviews of Interventions. Oxford: Cochrane Collaboration

Illich I. 1971. Libérer l'avenir: appel à une révolution des institutions. Paris: Éd. du Seuil

Jouvenel H de. 2004, An invitation to foresight. Paris: Futuribles. ISBN 9782843873041

Kahn H. and A.J. Wiener, 1967: the year 2000: a framework for speculation on the next 30 years. London. Macmillan Press. XXVIII-431 p

Kohlbacher F., 2006: The use of qualitative content analysis in case study research. Forum Qualitative Social Research. Vol 7, N 1, Art 21

Könnölä T., Scapolo F., Desruelle P., Mu R.,2011: Foresight tackling societal challenges: Impacts and implications on policy-making. Futures. 43(3):252-64

Kuusi O., Cuhls K., Steinmüller K., 2015: The futures Map and its quality criteria. European Journal of Futures Research. 3(1):1-14. doi:10.1007/s40309-015-0074-9

Leadley P., Alkemade R., Fernandez-Manjarrés J., Proença V., Scharlemann J., Walpole M., 2010: Scénarios de la biodiversité : projections des changements de la biodiversité et des services écosystémiques pour le 21 e siècle. Sec. de la Convention sur la diversité biologique, Montréal. Cahier technique $n^{\circ} 50$, 55 pages. ISBN 92-9225-219-4. ttps://www.cbd.int/doc/publications/cbd-ts-50-fr.pdf, 2010.

Mayring P., 2014: Qualitative content analysis: theoretical foundation, basic procedures and software solution. Klagenfurt. http://nbn-resolving.de/urn:nbn:de:0168-ssoar-395173

Meissner P., Wulf T., 2013: Cognitive benefits of scenario planning: Its impact on biases and decision quality. Technological Forecasting and Social Change. 80(4):801-14

Mermet L., 2005: Etudier des écologies futures: un chantier ouvert pour les recherches prospectives environnementales. Brussels: PIE-Peter Lang. ISBN 9789052012773. 
Mietzner D., Reger G., 2005: Advantages and Disadvantages of Scenario Approaches for Strategic Foresight. International Journal Technology Intelligence and Planning. 1(2):220-39

Miles I., 2010: The development of technology foresight: A review. Technological Forecasting \& Social Change 77 (2010) 1448-1456. doi:10.1016/j.techfore.2010.07.016

Millennium Ecosystem Assessment (MEA), 2005a: Working Group of the Millenium Ecosystem Assessment, 2005. Ecosystems and human well-being. Volume 1, Current state and trends, Washington (DC) ; Covelo (Calif.) ; London : Island Press, XXI-917 p. ISBN 9781559632270. https://www.millenniumassessment.org/en/Condition.html

Ministère de l'Enseignement supérieur, de la Recherche et de I'Innovation (MESRI), 2015. Stratégie nationale de recherche, France Europe 2020. http://www.enseignementsuprecherche.gouv.fr/pid25366/acces-thematique.html?theme $=317 \&$ subtheme $=318$

Moss R. H., Edmonds J. A., Hibbard K. A., Manning M. R., Rose S. K., van Vuuren D. P., Carter T. R., Emori S., Kainuma M., Kram T., Meehl G. A., Mitchell J. F. B., Nakicenovic N., Riahi K., Smith S. J., Stouffer R. J., Thomson A. M., Weyant J. P., Wilbanks T. J., 2010: The next generation of scenarios for climate change research and assessment. Nature: 463, 747-756. doi: 10.1038/nature08823

Morin E., 2011: La voie pour l'avenir de I'humanité. Paris: Fayard. ISBN 9782818501788

Neumann B., Vafeidis A.T., Zimmermann J., Nicholls R.J., 2015: Future Coastal Population Growth and Exposure to Sea-Level Rise and Coastal Flooding: a global assessment. Plos One 10(3): e0118571. doi: 10.1371/journal.pone0118571

Nowack M., Endrikat J., Guenther E., 2011: Review of Delphi-based scenario studies: Quality and design considerations. Technological Forecasting and Social Change. 78(9):1603-15

O’Neill B. C., Kriegler E., Ebi K. L.,, Kemp-Benedict E., Riahi K., Rothman D. S., van Ruijven B. J., van Vuuren D. P., Birkmann J., Kok K., Levy M., Solecki W., 2015: The roads ahead: Narratives for shared socioeconomic pathways describing world futures in the 21st century. Global Environmental Change,

Passet R., 1979: L'Économique et le vivant. Paris: Payot. ISBN 2-7178-3104-5

Phadnis S., C. Caplice, Y. Sheffi and M. Singh, 2015: Effects of scenario planning on field experts' judgment of long range investment decisions: Strat. mgmt J., 36; 1401-1411. doi: 10.1002/smj.2293

Program Millennium Ecosystem Assessment, 2005: Millennium Ecosystem Assessment Synthesis Report. Washington, D.C

Rasmussen, B. P. Dannemand-Andersen, 2009: Report: Review of science and technology foresight studies and comparison with GTS2015 . ISBN 978-87-923-7277-2. https://en.gts-net.dk/wpcontent/uploads/2014/04/ris\%C3\%B8.pdf

Raupach, M. R., A J. McMichael, J. J. Finnigan, L. Manderson, and B. H. Walker 2012: Negociating Our Future: Living Scenarios for Australia to 2050. Australia: Australian Academy of Science. https://www.science.org.au/publications/australia-2050

Raven P. G., 2013: The future's four quaters: Proposing a quadrant methodology for strategic prototyping in infrastructural context. Technological Forecasting and Social Change. 84: 115-130. doi: 10.1016/j.techfore2013.10.102

Roberts C. W., 2000: A conceptual framework for quantitative text analysis. In Quality \& Quantity 34: 259-274, 2000. Kluwer Academic Publishers.

Schwartz P., 2007: The Art of the Long View: Planning for the Future in an Uncertain World. Chichester: John Wiley \& Sons. ISBN 978-0-471-97785-8.

Starr B. E, 2002: Structure of Max Weber's Ethic of Responsibility. In Journal of religious ethics. Vol27. Issue 3. 407-434; https://doi.org/10.1111/0384-9694.00025

Tapinos E., 2012: Perceived Environmental Uncertainty in scenario planning. Futures. 44(4):338-45; doi:10.1016/j.futures.2011.11.002

Van der Heijden K., 1996: Scenarios: The Art of Strategic Conversation. Chichester, England; New York: John Wiley \& Sons; XIV-305 p., ISBN 0-471-96639-8.

Vecchiato R. and C. Roveda, 2010: Strategic foresight in corporate organizations: Handling the effect and response uncertainty of technology and social drivers of change Technological Forecasting and Social Change 77 (2010) 1527-1539. doi:10.1016/j.techfore.2009.12.003

Vecchiato R., 2012: Environmental uncertainty, foresight and strategic decision making: An integrated study. Technological Forecasting and Social Change. 79(3):436-47. doi:10.1016/j.techfore.2011.07.010 Viveret P., 2003: Reconsidérer la richesse. La Tour d’Aigues: Éd. de l'Aube. ISBN 2-87678-884-5 
Weber Max, Peter R. Baehr; Gordon C. Wells, 2002 (1905): The Protestant ethic and the spirit of capitalism and other writings. Penguin. ISBN 978-0-14-043921-2.

\section{CVs of authors \\ Denis LACROIX}

Denis Lacroix is in charge of foresight and scientific watch at Ifremer, French national institute of research for the exploitation of the sea. Since 2006, he carries out foresight activities to enlighten Ifremer strategy. He is co-leader of the French environment research network AllEnvi foresight group and in the Prosper network (linking French national research public institutes). His fields of expertise encompass mainly aquaculture and coastal management with 16 years of experience in overseas territories and at the FAO. Engineer in agronomy, PhD in animal sciences, he delivers lectures in 6 institutions and universities, in France and abroad.

\section{Louis LAURENT}

Since 2011, Louis LAURENT has been director of research funding and scientific watch at ANSES (French Agency for Food, Environmental and Occupational Health \& Safety in France). After a career as a physicist at the French Alternative Energies and Atomic Energy Commission until the late 1990s, he held positions related to the management of research: Director of Institute at CEA (the current "Institute Radiation Matière" de Saclay), head of the information technology and nanotechnology department at the French National Research Agency and scientific manager of the Campus Paris-Saclay project.

\section{Nicolas de Menthière}

Nicolas de Menthière, a former student of the Ecole Normale Supérieure (Biology), is Director of Foresight and Scientific Watch at IRSTEA, the French research institute of science and technology for environment and agriculture. He joined IRSTEA in 2001 in charge of information system and communication. Since 2009 he carries out foresight activities to enlighten IRSTEA strategy and advise public policy makers. He is co-leader of the French environment research network AllEnvi foresight group. He has been head of the wood research and technology office of the Ministry of Agriculture.

\section{Bertrand Schmitt}

Bertrand Schmitt, Senior Researcher in Economics in the INRA (French institute for agricultural research), is the head of the INRA's delegation for scientific expertise, foresight and advanced studies since 2013. Between 2013 and 2017, he was co-leader of the French environment research network AllEnvi foresight group. He was previously Head of the national Department of Social Sciences in the INRA and Head of the Centre of economics and sociology applied to the agriculture and the rural areas in Dijon (France). He worked on economic mechanisms of firm and household location, on factors of the local economic growth and on economic assessment of regional development policies.

\section{Audrey Béthinger}

Audrey Béthinger, an ethologist and an agronomist, is head of project in prospective at INRA (the French National Institute for Agricultural Research) within INRA's Expertise, Foresight and Studies department since 2014. She joined the institute in 2004, first as head of technical communication at GEVES, then at INRA's headquarters, as facilitator of the network of communication officers.

\section{Bernard David}

Bernard David is Scientific Advisor to the Director of the strategy and programs of the French Atomic Energy Commission (CEA), for strategic watch and foresight issues. He previously held various positions as Project Manager for the creation of the French Academy of Technologies, Technical Advisor to the Office of the High Commissioner for Atomic Energy, Project Manager for applications of sciences to the French Academy of Sciences, etc. He began his career as project manager for the development of nondestructive tools and testing methods, field in which he holds several patents. He graduated from the Ecole Supérieure d'Electricité. 


\section{Christophe DIDIER}

Christophe DIDIER is Deputy Scientific Director of INERIS. He coordinates INERIS technical support to the Ministry in charge of environmental issues. He is coordinating emerging environmental risk identification activity. He is member of several Europeans boards, notably relative to raw material and environmental protection. For more than 15 years, he worked as international expert in mining, mine closure, natural hazards, underground storage as well as unconventional hydrocarbons promoting integrated risk analysis approaches. Christophe Didier graduated from Mines ParisTech as Engineer.

\section{Jacques PARENT DU CHATELET}

Jacques Parent du Chatelet is the Deputy Director of Research at Mété-France, head office of SaintMandé. He published or co-published in peer-reviewed journals on sea-surface observation by skywave radar, rain and wind velocity measurement by weather radars, and radar signal processing in general. His research activity is now centered on Doppler processing and low level atmospheric refractivity measurement by radar. He was born in France in 1952 and received his Ph.D. degree from the University Pierre and Marie Curie, Paris France in 1977.

\section{Highlights}

- A French foresighters team had been asked to cluster the main environmental scenarios described in international studies.

- The synthesis of the 307 scenarios described in 99 studies highlighted 11 societal and environmental pathways.

- Those 11 pathways can be clustered in 3 groups: Decline, No priority to environment, With priority to environment.

- Governance, economy and societies, in that order, showed to be the main drivers of the scenarios.

- Ocean, coastal areas and forest are rarely cited as driving factors for environmental scenarios. 